\title{
Resonance as a Social Phenomenon
}

\author{
by Vincent Miller \\ University of Kent
}

Sociological Research Online, 20 (2), 9

$<$ http://www.socresonline.org.uk/20/2/9.html>

DOI: $10.5153 /$ sro.3557

Received: 29 May 2014 | Accepted: 19 Jan 2015 | Published: 31 May 2015

\begin{abstract}
This paper is a theoretical investigation into the question of affinity and belonging in everyday life contexts. I argue that Sociology had tended to focus attention on the conceptual binaries of 'individual/community' or 'individual/social structure' when discussing experiences of inclusion, solidarity or belonging in social life. This has meant that such experiences are generally conceived in terms of 'a part of' or 'apart from'. Such a focus has meant that incidents of belonging or affinity which lie between these extremes and which may be intense, intimate and meaningful, but at the same time fluid, ephemeral or tenuous tend to escape sociological analysis.

Largely inspired by sociological phenomenology, but multi-disciplinary in nature, this paper will try to address this issue by positing 'resonance' as a useful concept by which sociologists and social scientists more generally, can engage with the more fluid forms of belonging and affinity achieved in everyday life contexts.
\end{abstract}

Keywords: Resonance, Intimacy, Everyday Life, Communitas, Anonymity, Phenomenology

\section{Introduction}

In activating the spectacle of anonymity, the situation of action arouses the need and desire for its mastery. Culture then initiates the mastery of anonymity in representations of moments of renewal imagined as the promise of concordance, of intimacy.

...Such a landscape saturates the city with an aura of unbounded and, yet, unfulfilled intimacy; the city constantly makes itself an image between these extremes (Blum 2003: 286-287).

1.1 From its very beginnings, Sociology has been a study of the breakdown of belonging, in the sense that the discipline has generally characterised the processes of modernisation and urbanisation as dissolution of long-lasting, intimate social ties as a counterpoint to the rise of individualism. This is epitomised in many of the canonical works of the discipline, including the major studies of Tönnies, Weber, Durkheim and Simmel. In each of their major works, modern cities are depicted as places of anonymity, anomie, instrumentalism, blazé attitudes, and individualism: modern cities break down 'community'.

1.2 Without debating the validity of these claims, what Blum does in the passage above is question what has become a somewhat simplistic portrayal of everyday life in the late modern city. He suggests that the city presents to its inhabitants an image that oscillates constantly between the extremes of boundless opportunities for sociality and intimacy, on the one hand, and anomic individuation on the other: that intimacy and anonymity, individualism and belonging, exist simultaneously.

1.3 Everyday experiences speak to this. Much of the time, modern urban life provides us with the experience of anonymity: parades of the faceless at busy intersections; instrumental and bureaucratic interactions involving institutional or commercial exchanges; and the use of mass transit. However, it is also clear that intimacy and communion can be experienced at the heart of large scale urban happenings during, for example, sporting events, rallies, concerts, mass funerals, as well as in micro interactions which take place in the conversations among strangers in pubs, the collective sensory experience of a small music venue, or the familiar banter in a local market. In circumstances such as these, we feel a sense of connection, a momentary 
experience of belonging and understanding with others we do not even 'know', and who, in other contexts, would be anonymous to us.

1.4 The sociological tradition, generally, has been the investigation of enduring social structures. The definition for sociology itself ("the study of the development, structure, and functioning of human society', OED) demonstrates the central importance of structures within the discipline. It has proven difficult to talk about forms of association that lie in between these extremes: ones that are not fixed, longstanding and stable (like communities and social structures), but are vague, fluid, ephemeral, and even ad hoc, yet still involve forms of intimacy and genuine experiences of belonging.

1.5 To a certain extent, this has left sociology somewhat blind to these more ephemeral forms of collective phenomena. That said, there have been a number of attempts in the sociological literature to conceptualise such experiences. However, these have either focussed on such phenomena as exceptional as opposed to constitutive of everyday life, or have in general under-theorised and ill-defined. This paper attempts to explore these more fluid, dynamic and ephemeral forms of belonging and intimacy that occur between the traditional poles of 'individual' and 'community' or 'social structure' through the concept of 'resonance'.

In physics, resonance refers to 'the reinforcement or prolongation of sound by reflection form a surface or by synchronous vibration of a neighbouring object' (OED). Systems and objects possess resonant frequencies in which a small amount of input can produce large oscillations. Thus, resonance is an amplification or reverberation phenomena of interacting bodies in which the least effort produces the greatest effect, producing vibrational energy exponentially higher than its input (Mühlhoff 2014). One could say that resonant interactions produce a result that is, in many ways, greater than the sum of their parts.

1.7 I propose a place for this term in sociology. Although under theorised and used sparingly, resonance has proven useful in a number of areas in sociology, particularly in social movement studies. However, given the disparate and inconsistent use of the term, there is a need to go outside the confines of sociology and into, for example, anthropology and philosophy to try to articulate a concept which has been used in a variety of disciplines.

1.8 Thus, this paper, to a certain extent, is an exercise in creative thinking around a phenomena which is a fundamental part of social experience, yet under theorised and poorly explained in sociological research. As difficult a task as this may be, it is an important one for sociology because the over-emphasis on a set of abstract binary concepts such as individual/community or individual/social structure effectively ignores a whole set of experiences which have profound effects on the way society is held together and experienced.

1.9 On the way, I shall review previous sociological work which has engaged with resonance, or similar concepts, in classical sociology, phenomenological sociology, qualitative methodology, the sociology of social movements, anthropology, and the recent affective turn inspired by the work of Deleuze. This paper will engage with these conceptual formulations with a view to defining and outlining the key characteristics of resonance as a workable concept within sociological discourse, and conclude by outlining the potential contribution that resonance could make to various sub-fields in sociology.

\section{Collective effervescences as exceptional social forms}

2.1 Turner (1969) suggested that both sociologists and anthropologists tend to identify 'the social' squarely with the 'socio-structural' (Olaveson 2001). Indeed, sociological work has tended to polarise collective experience into one of two types of phenomena. On the one hand, there is the long-lasting and usually formalised concept of 'community' which in itself is one of the most important, but most vague and complex terms in the social sciences ${ }^{[1]}$.

2.2 Often couched in nostalgia, 'community' from Tönnies onward, has generally been seen as an enduring form of belonging that not only provides a sense of identity, but also sets the foundation for social relations based on mutual and collective interest. On the other hand, sociologists from Marx onward also see enduring social relations as embodied through social structures such as economic relations, law, religion, and other forms of institutionalised power. These help to create 'the social' as enduring and also tend to maintain the status quo. In either case, the emphasis within the study of society tends to focus on such collectively maintained, enduring structures. At the other end of this binary sits the atomised individual, the antithesis of sociological analysis in contradistinction to 'society', 'community' and 'social structure'. 
The key exception to this discourse within classical sociology is Emile Durkheim who, particularly in The Elementary Forms of Religious Life, referred to 'collective effervescences'. Although Durkheim's use of this term is ill-defined, he refers to the emotional stimulation which emerges from 'the very act of congregating' (Durkheim 1912/1995: 218) under certain circumstances such as rituals, religious rites and the like. Such experiences are liminal for Durkheim, occurring outside the normal conditions of mundane life, and these episodes are said to produce, recharge and re-enforce communal emotional connections that can be worn down by the anomie created through social structures (Misztal 2003). So although the complexity of modern industrial living is said to create anomie and isolation, through periodic experiences of collective effervescence, subjects are able to reach beyond their individuality and atomisation and towards a collective, embodied, emotional experience (Shilling \& Mellor 1998, 2011).

2.4 Turner's concept of 'communitas' can be seen as the functional equivalent of collective effervescence (Olaveson 2001). Communitas is posited as a transitory or ephemeral form of bonding involving a kind of collective delirium or ecstasy. Again, these experiences are said to exist outside of the normal social existence of a community, and are seen sources of great cultural creativity and renewal. Turner, like Durkheim, sees communitas as counterbalancing the alienating effect of social structures.

2.5 In sum, the key aspects of collective effervescence (and communitas), as suggested by Olaveson (2001) and Shilling \& Mellor $(1998,2011)$ include a communal or collective bonding event incorporating intense passion or emotion, where such events are temporary or ephemeral in nature; experiences of intense intimacy and immediacy, which are created through will and attention, and thus are not spontaneous or ad-hoc. These are periods of great social creativity and renewal (even violence) and these events are the result of ritual or similar such exceptional occasions in society. Lastly, these effervescences are embodied through proximity to others, and through shared emotions such as euphoria, and experiences of intoxication.

2.6 The idea of collective effervescence has been picked up by neo-Durkheimians such as Maffesoli (1996) and Mestrović (1993). Mafessoli developed the concepts of the neo-tribe ${ }^{2]}$ to posit a contemporary reconstruction of social life less inclined towards institutions, class and other social structures and towards more temporary, affinity-based social bonds which come into being during occasions and rituals, such as 'rave' events or festivals[3].

2.7 While Mafessoli has a very positive outlook on the collective effervescence that underlie the concept of neo-tribes, Mestrović (1993) emphasises the negative emotional manifestations of the effervescences of fear and hatred in contemporary culture (Shilling and Mellor 1998). The xenophobic or destructive potential of collective effervescences for Mestrović leads to increases in ethnic and racial conflict and the cultivation of 'barbarism' in late modernity. For Shilling and Mellor, neither Mafessoli not Mestrović fully consider the ambivalent nature of collective effervescence[4].

2.8 In an overview of the concept, Misztal (2003) takes exception to the suggestion that collective effervescences, when they occur, create emotional bonds in a society filled with anomie. This suggestion would appear to be circular in the sense that such rituals would have to depend on strong bonds in order to occur in the first place. Second, he notes that Durkheim presents the sort of rituals in which collective effervescence occurs as extraordinary events, thus excluding from consideration many less-intense and less formal ways of producing social solidarity. He objects to the emphasis that Durkheim places on these exceptional periods as times of primary bonding and renewal, as it can be argued that such an emphasis overlooks fundamental bonds that are created during calmer times or during routine (Misztal 2003:48).

2.9 These criticisms address directly the idea that incidents of collective effervescence exist outside of everyday life. What we are presented with by Durkheim (and Turner), is a social world which in everyday experience is dominated by social structures, producing an alienating effect where any sense of shared presences, belonging or common purpose are occluded by a mutual dependence within a system. Thus subjects become increasingly isolated and individualised, only occasionally being brought together through intense rituals involving delirium or intoxication. As the criticisms of Misztal above suggest, this infers that everyday life itself provides little in the way of bonding opportunities, either in renewing bonds that already exist, or creating new bonds where none existed previously. In other words, Durkheim presents us with an everyday life which is devoid of intimacy.

\section{Everyday life and phenomenological intimacy}


Simmel (1949), in 'The sociology of sociability', acknowledged everyday forms of association (sociability) that are beyond instrumental or practical interest, but contain within it 'a feeling of the worth of association as such' (Simmel 1949: 255). Here, Simmel is trying to unpick the mundane aspects of being together in purely social circumstances, where being together is not about accomplishing goals or tasks, but merely to enjoy the company of other humans. However, Simmel's characterisation slots very much into the mendacity of everyday life, as this 'good feeling' lacks any profound emotion or connection, and is really more akin to Malinowski's (1923) concept of phatic communion. This refers to the type of bonding which occurs through the exchange of pleasantries, small talk, bodily gestures, and other forms of acknowledgement and recognition of others when in physical proximity. The point of these exchanges is not to exchange meaningful information or content between persons, but instead to maintain social bonds and the potential for later meaningful communication, should it be needed. Sociality and phatic communion can thus be seen as providing the foundations for potential belonging and intimacy within seemingly anonymous environments.

3.2 The last two decades have, seen a surge in academic interest on the topic of intimacy. During the 1990 's in particular many authors produced work which was influential in re-investigating human relationships through the discourse of intimacy (Giddens 1992; Duncombe \& Marden 1993; Plummer 2003; Zeldin 1995; Jamieson 1998, 1999). By and large, these writings investigated notions of intimacy, romantic love, and close human relationships under the challenges of late (or 'post') modernity and the context of 'individualisation' as formulated by Beck (1995), Bauman (1991) and Giddens (1992). Some work, such as Jamieson (1998) and Roseniel \& Budgeon (2004) extends the concept beyond the romantic relationship to include friends, family, and care-givers. In all these cases the themes of love, deep or close association, everyday acts and familiarity are still prevalent and seen as fundamental to the experience of intimacy. Here, the concept of intimacy denotes belonging and emotional attachments gained through familiarity, closeness and routine, and stands in contrast to the extreme events of collective effervescence.

3.3 This more broad notion of intimacy as familiarity, knowledge, and routine has featured in the work of phenomenologically-inspired sociologists, such as Alfred Schutz and José Ortega Y Gasset, who have used the term in a way that avoids the binary oppositions mapped out at the start of this paper. Similarly to Blum, both Schutz and Ortega Y Gasset see the social world as organised simultaneously in terms of familiarity and strangeness, or intimacy and anonymity (Schutz 1944; Ortega Y Gasset 1957; Herrida-Lazcono 1996; Dunscombe and Marsden 1993). For Schutz in particular, these experiences of intimacy and anonymity are central as they influence how we typify, and therefore experience, the social world around us (Natanson 1986).

3.4 The point of departure for Schutz in terms of social life becomes the 'here and now' and the practical face-to-face engagement with others while going about the daily business of life. The 'here' not only describes a temporal-spatial proximity, but also a social proximity in that what can be achieved in the here-and-now is a sense of understanding the other as living a similar subjective experience as oneself (intersubjectivity), a kind of direct, pure, unmediated social experience which Schutz refers to as the 'we-relation'.

3.5 In this way, phenomenologists like Schutz and Ortega see intimacy, intersubjectivity, or reciprocal understanding, as the foundation of social life which is then expressed in varying degrees of anonymity as one moves outward towards social experiences that are less proximal (in either spatial dimensions or in levels of understanding) and more mediated by relying on what Schutz termed 'typifications'.

3.6 Schutz sees anonymity as phenomenological uncertainty or indeterminacy, whereas intimacy drifts towards concreteness or a certainty of one's experiences with others [5]. When we feel known and know others, our experiences are more certain, in what Schutz termed the 'vivid present'. Thus the sharing of a common experience of time, space, and recognition can move us towards the simultaneity of two (or more) streams of consciousness in the experience of the 'we' relationship. This 'we' is where we experience intimacy and, relatedly, increased levels of mutual understanding and engagement with others. The point is that intimacy is something achieved through empathetic understanding: through taking into account and the acknowledging of others, and that their experience of events in the 'here and now' are similar to our own.

3.7 This approach has had its influence outside sociology where, for example, authors such as Coburn (2001) mark out the concepts of 'certainty' and 'similarity' as a key aspect in human relationships and a sense of belonging with others:

In this view, one individual's subjectivity is not seen as particularly closer to 'objective truth' or reality than another, but rather, the points of convergence of two or more subjectivities provide the matrix for an emotional resonance process 
Coburn describes this process of resonance as 'quintessentially human', referring to the effort amongst individuals to achieve a 'sameness' and therefore a certainty of their own experiences with the people around them. For Coburn, Schutz, and Gassett, these efforts are not exceptional nor ritualistic, but part and parcel of the overall process of social life.

\section{Qualitative methodology and momentary 'sameness'}

4.1 One of the methodological challenges of qualitative research particularly ethnography and interviewing in sociology and the social sciences more broadly, is the problem of credible understanding: how researchers can attempt to achieve some sort of legitimate understanding of another's world or how 'other' social worlds can be approached by researchers.

4.2 Of course, sociologists and others talk about 'verstehen' and how researchers should use the human faculties of empathy to begin to approach the viewpoint of the other, an intellectual and emotive exercise which attempts to see the world from someone else's shoes, engage with them on their terms, or to see the world from their perspective. While verstehen as commonly understood can be criticised as an impossible and naive ideal (and even a silencing of the other's voice, see Shields 1996), in the work of phenomenological philosophers, it refers to the recognition that we consider each other's actions and words not as physically caused, but as the product of a dialogical relationship where interpretation of each other's gestures becomes the basis of a common reality created in the moment of interaction (Dautenhahn 1997). Practically, this means that what qualitative researchers attempt to do, in interviews for example, is to try to look for or achieve a degree of 'sameness' in the face of diversity using whatever commonality of experience may exist to achieve credibility, and therefore a rapport.

4.3 In many ways, the interview process is a good illustration of these efforts, and the methodological discussion which surrounds interviewing gives us useful insight into face-to-face social interactions which are intimate, but also temporary and fluid. Thoughtful consideration of interviewing demonstrates that an interview is not a method for 'getting information', but a vehicle for creating personal texts and performances (Denzin 2001). It is an interpersonal situation in which interviewer and interviewee react in relation to each other and reciprocally influence each other (Kvale 1983) which produces data constituted by the interaction itself (Sullivan 1954; Gubrium and Holstein 1998). In that sense, the interview process does not bring access to an essential self, or an objective narrative of 'real world' events, but brings forth through the interaction of the interview situation, a version of selves (both interviewer and interviewee) which strives to give a coherent account of one's life and events (Denzin 2001; Gubrium and Holstein 1998).

4.4 Such relationships not only demonstrate the 'in-the-moment' co-construction of selves and intimacy, but the fluid nature of 'sameness', or inclusion and exclusion made 'on the fly' based on particular circumstances. For example, Song and Parker (1995) provide an account of the dynamic nature of inclusion and exclusion their experience of interview process, as Korean-American and Chinese-English researchers interviewing ChineseEnglish young people. Both experienced periods of 'sameness' and 'difference' with their subjects during the interview process:

\footnotetext{
Claims of commonality or difference by interviewees, therefore, did not necessarily shape the interview process in predictable or systematic ways; such claims were very much contingent upon each moment in each interview... For us, not only difference, but aspects of commonality, were key in shaping our relationships with our interviewees. Binaries such as 'black/white' and 'insider/outsider' often put too much emphasis upon difference rather than on a partial and simultaneous commonality and difference between the researcher and the interviewee (Song and Parker 1995: 248-249)
}

4.5 The experience of Song and Parker suggest moments of 'sameness' associated with resonance are unstable, dynamic and contingent and that we experience the other with different levels of immediacy, intensity, and intimacy. Thus, Song and Parker experienced both resonance and dissonance at different points with the same interviewees. This association is fluid, ephemeral, and, if successful, meaningful. However, it is an association based very much in the 'here and now' moment of the interview: a situation of both parties working towards a common product (the interview and the interview transcript).

4.6 This emphasis on the interpretive moment sits well within the phenomenological emphasis on the 'here and now'. Coburn (2001) is suggesting a similar process in the therapeutic relationship, in which he engages with the concept of emotional resonance: 
Emotional resonance is an individual's signal to another that 'I am present with you, regardless of our differences'... This process is quintessentially human and is affected paradoxically via our human similarities and sameness, on the one hand, as well as via our substantial discrepancies in our personal subjectivities on the other. (Coburn 2001: 309312).

4.7 It can be suggested that the kinds of interpretive moments referred to by Song and Parker, and Coburn are emblematic of what we experience in social life and in everyday contexts: a seeking out some sense of momentary sameness, common ground, or meaning with others 'on the fly' or in the 'here and now' in order to help ourselves accomplish tasks and make life more enjoyable.

4.8 However, points of 'sameness', understanding, or belonging can be tenuous. This is not only true of the here-and-now moment of the interview, but the meaning of the text produced by the interview, which again, gets incorporated into the narrative of a piece of research. The social interaction of the interview, and that of the text produced by them, has an unstable ontology. Their meaning is created in the moment, and their significance over time is dependent on how certain texts can achieve a tenuous meaning and significance through reconstruction (Dimock 1997).

4.9 Beyond the interview, social life itself is filled with such examples of ephemerality. Within the contexts of romantic relationships, one can look back at previous relationships which may have possessed significant and profound meanings for us at one point in our lives, and now look back upon those with very little emotion. Books or songs, experienced at different times, can create entirely different interpretations and meanings in the same person. One can gain new insights and discover hidden depths and salience to a book upon multiple readings, or equally, upon second reading really appreciate how a specific text may have been 'of its time' and express very little relevance to the same person at a different stage of life.

4.10 The resonance metaphor emphasises meaning, as an ephemeral process which occurs in here and now contexts. Within social circumstances, this emphasis can be placed on the temporary and circumstantial nature of belonging and inclusivity. Here, the research interview was used as a small-scale example of how a momentary, fluid, yet potentially profound resonance can be achieved in here-and-now contexts.

\section{Resonance and social movements}

5.1 In the fields of social movement studies and activism, recent work has highlighted the importance of emotions in the success and sustenance of social movements. It is suggested that social movements have 'emotion cultures' that facilitate or impede collective action (Robinett 2012). Here the concept of resonance has perhaps made its greatest usage in sociological research, despite the term not being operationally defined in a way that separates the phenomenon of resonance from the outcomes it is claimed to produce (Ferree 2003). In other words, in social movement studies, resonance is both seen as a factor crucial to the success of a social movement, but resonance is also considered to evidence the achievement of that success.

5.2 In this body of literature, cultural resonance is depicted as an appeal on the basis of a common experience (Snow and Bentford 1988; Ettema 2005; Ferreira 2004). Ferree (2003) defines resonance as 'the mutually affirming interaction of a frame with a discursive opportunity structure supportive of the terms of its argument' (Ferree 2003: 310), however, the literature itself points to a distinction betweencultural resonance and emotional resonance. Cultural resonance is associated with the extent to which a movement and its message are compatible with larger societal values and norms and draws from a familiar cultural repertoire (Robinett 2012; Bedford and Snow 2000). Culturally resonant messages need to be both salient (i.e. a topic of importance to one's life), and commensurable (i.e. credible and understandable given one's life history and experiences) in order to be successful in attracting mainstream support.

5.3 By contrast, messages and movements which have emotional resonance are more likely to be radical or oppositional in nature, not necessarily appealing to mainstream values and thus 'sameness' on the larger scale of mainstream culture. Indeed, emotionally resonant messages have more opportunity to be divisive and dissonant with mainstream culture, as social location in terms of class, gender and ethnicity are seen to play a more significant role in emotional resonance (Robinett 2012).

5.4 Nonetheless, studies of journalism and activism demonstrates resonance as a key component in message production which allows activist reporting and storytelling to strike a chord with readers, thereby encouraging certain kinds of (moral) evaluations in audiences. In other words, resonance is seen as important in order for journalistic accounts to have an impact on audiences and motivate them towards action. 
Resonance is a matter of commensurability to our lived experience - that is to say, a goodness of fit to our past: it is also a matter of empirical credibility - a goodness of fit to what we know of the current moment. (Ettema 2005: 147)

Resonance in journalism is created through emotional appeals that transcend the mere transmission of information, but also appeal to common experience to enact a bond between the events being portrayed and the reader.

\title{
Resonance as embodied practical intimacy
}

\begin{abstract}
...people, in the performance of their tasks, also attend to one another. Looking back, we can see that Durkheim's error was to divorce the sphere of people's mutual involvement from that of their everyday practical activity in the world, leaving the latter to be carried out by individuals in hermetic isolation. In real life, this is not how we go about our business. By watching, listening, perhaps even touching, we continually feel each other's presence in the social environment, at every moment adjusting our movements in response to this ongoing perceptual monitoring... Indeed it could be argued that in resonance of movement and feeling stemming from peoples mutually attentive engagement, in shared contexts of practical activity, lies the very foundation of sociality (Ingold 1993: 160, my emphasis).
\end{abstract}

6.1 The doing of life is an ensemble which involves others. In thoughtful passages such as the above analysis of 'The Harvesters', a medieval painting by Pieter Bruegel, Tim Ingold uses 'resonance' as a way to describe people's mutually attentive engagement in shared contexts of practical activity. This experience of attending to one another, feeling each other's presence in performing common tasks in common contexts is, he argues, fundamental to our experience of the everyday world and the spaces we inhabit.

Resonance, and the intersubjective 'sameness' that it implies, should not be viewed abstractly, merely as a cognitive exercise in understanding, interpretation or even emotional identification (which has been the focus of most of the literature thus far), but a lived reality involving bodies, action and movement. Thus, some anthropologists, such as Wikan (1992) have, like Ingold, been inspired by the Heidegger and other phenomenology-inspired work which emphasises 'doing' and 'dwelling' as constitutive of human existence. For Wikan, the concept of 'culture' is an abstraction that evokes difference by separating subjectivity, identity and language from the doing of life, whereas resonance relies on common practical and emotional experiences, connoting 'sameness' in feeling-thinking engagements in the practical world, a sameness which goes beyond words or abstract thought, and is instead cultivated through the mutual being-there of practical human experience which intertwines feeling, thinking and doing. Similarly, Shilling \& Mellor (1997) suggest both 'cognitive apprehension' and 'carnal knowing' as two different ways of gaining knowledge of the world.

6.3 Resonance is not only an appeal to common understandings and experiences, it is felt and performed in and though the body: an emotional experience and an embodied one involving the presence of others. Schutz (1964) recognises this as well, and describes these more subtle dimensions in the essayMaking music together', in which he used the performance of music as a metaphor for the kind of intersubjective understandings which occur in everyday life and are not tied into formally expressed systems of meaning (Malhotra 1981).

6.4 In what he awkwardly calls the 'mutually tuning in relationship', he argues that in the performance of music, musicians, and audience as well, experience the 'we' relation as a vivid presence, where co-performers and listeners are living in the same flux, all living simultaneously in several dimensions of time: 'outer duration' (measured time) and 'inner duration' (experienced time), in which the content of the music played actualises itself; each, simultaneously, shares in vivid present the others stream of consciousness in immediacy (Schutz 1964: 176)

6.5 As a musician himself, the point that Schutz was trying to make was that making music together is not only an intellectual exercise: it is co-constructed through the interaction of bodies. The 'individual' musician not only plays his or her own instrument, interpreting their part, but also understands how this part is fragmentary of the whole, one that is ultimately greater than the sum of the parts[6]. The musician has to involve others and to anticipate the interpretations of the other musicians around him or her. In that sense, the face-to-face performance of music is beyond language or structure, involving eye contact, facial expressions, and intonation of notes from instruments. These all become clues as to the meanings and intensions of the other performing musicians that are essential in a performance where explicit conversation and direct expression of meaning and intension is impossible.

6.6 This refers back to Mead's (1934) notion of 'a conversation of gestures', where unconscious communication is made through gesture, stance, pause, and by which all others unconsciously and continually 
readjust their position in a process akin to feedback or reverberation, to create a social situation, or in this case, a dog fight:

The very fact that the dog is ready to attack another becomes a stimulus to the other dog to change his own position or his own attitude. He has no sooner done this than the change of attitude in the second dog in turn causes the first dog to change his attitude. We have here a conversation of gestures (Mead 1934: 42-43).

6.7 Similarly, musicians can feel through such embodied gestural relations with other musicians when to change the volume, tempo, intonation, or even when to end the song through the intimate connections that are made and reinforced through gesture, glance, intonation and a bit of background knowledge of musical form and genre.

6.8 This musical analogy can be a bit more directly linked to everyday life through the anthropologist Tim Ingold, (who also happens to have a better knack for terminology than Schutz). In 'The temporality of the landscape', Ingold argues that, like music, socio-spatial life is created and comes into being in and through performance, and that both social life and music are a complex interweaving of cycles, interpretations, and tasks. He suggests that what we think of as 'landscape' should be thought of more as 'taskscape': that 'landscape' is neither land, nor nature, nor space, but an ensemble of tasks or practical operations that are performed in the normal business of life. In other words: acts of dwelling. It is in the enactment of taskscapes where a coordination of bodies, presence and purpose is actualised in resonance.

\section{Affective Resonance}

7.1 In a recent extended discussion, Mühlhoff (2014) tries to articulate a concept of resonance for the cognitive sciences which emphasises the embodied aspects of social interaction by focussing on the notion of 'affect', or the body's inherent capacity to affect and be affected, and the resonant forces produced by such interactions. He defines affective resonance as:

\footnotetext{
...processes of social interaction whose progression is dynamically shaped in an entanglement of moving and beingmoved, affecting and being-affected. This affective interplay is experienced by the involved interactants as a gripping dynamic force, which is highly sensitive to the concrete relational and situational configuration. It is a key characteristic of affective resonance that its concrete processual unfolding is an irreducible product of the relational entanglement and cannot be broken down to individual behavior or individual affections in the sense of 'inner feeling states' (Mühlhoff 2014:1).
}

7.2 The key points he attributes to affective resonance are that it is a co-production of sense and meaning created through Being-in-relation. That is, resonance is a product of relational subjectivities (not independent 'selves') that are in the process of 'becoming'. This becoming is mutually constitutive and allows for the coproduction of phenomena which go beyond individuals, their states, and their understanding of meaning.

7.3 Affective resonance is thus not 'coordination' of movements (as perhaps suggested by Ingold above), as that implies a meeting of individuals, but a relational dynamic force which can be seen as a higher order derivative of the social interaction itself. In that sense, resonance is a qualitatively distinct entity, not the sum of, or a collection of, individual behaviours is encompasses. It can be considered what Deleuze (1991, 1994) refers to as a 'virtual': an aspect of reality which may be caused by material interactions, but is not material or actual in itself.

7.4 What is desirable about this conception of affective resonance is the emphasis on the body as central to the experience, and the articulation of the idea that resonance itself can be a social entity which is distance form social structures as well as the experience of individuals. However, the overriding emphasis on affected states of the body, and of the co-production of subjectivities in the present moment, perhaps comes at the expense of any sense of common ground, understanding, or intersubjectivity as part of the experience. Affective resonance comes across as 'gripping' but not particularly meaningful or profound. Mühlhoff himself suggests 'Affective resonance is a subtle and partial phenomenon, pervading most face-to-face social interaction' (Mühlhoff 2014: 1), and in that way, it seems as though little separates resonance from the phatic nature of Simmel's 'sociability' discussed at the beginning of this paper. Thus, while Durkheim's collective effervescence may be too exceptional, affective resonance may not be exceptional enough. It is, however, a valuable and lucid conception of resonance as a distinct social entity existing outside the concept of 'structure'.

\section{Conclusion: key elements of a theory of resonance}

Human beings give short-lived meanings to long-lived worlds. ( Dimock 1997) 
8.1 Massey (2005) suggested to geographers that space can be seen as an 'event' or a process that is open to multiple experiences and modalities, and is always in the process of 'becoming'. This paper is suggesting that within everyday life, belonging and affiliation can be (and often is) an 'event' as well: a tenuous event which momentarily ties together subjects and spaces intersubjectively into a face-to-face context of the here and now.

8.2 This paper has negotiated a fairly eclectic path through a variety of literatures in an effort to distil the key elements with which we can conceptualise resonance as a social phenomenon. A review of Durkheim's notion of collective effervescence demonstrated the power of short-lived, co-present, euphoric and intense rituals in overcoming anomic social structures and re-establishing communal emotional bonds. Phenomenological sociology moved these experiences from the exceptional to the everyday experiences of intimacy and belonging created in 'on the fly', 'here and now', moments of face-to-face proximity. A consideration of the literature around qualitative interviewing demonstrated how intersubjective 'sameness' can be achieved through empathy and through appeals to common human experiences, while also noting how tenuous and fluid inclusion and exclusion can be from moment to moment. These appeals to common experience to create emotional connections is prominent in the literature on social movements, which utilises cultural and emotional resonance as a way to explain the success of social movements in motivating people into activism and fermenting social change.

8.3 From these more 'cognitive' dimensions, we moved onto anthropological literature, which has used resonance with a particular emphasis on embodiment, practice, and task-oriented co-presence. Inspired largely by Heideggerian notions of 'dwelling' and 'Being-in-the-world', this literature focusses on how understanding and affinity among social actors cannot be divorced from the physical doing of life. That the co-presence of bodies, mutually engaged in common tasks, the exchange of gestures, creates understandings and affinities which go beyond abstract, cognitive, or structural notions of identity, community, belonging or understanding. The focus on the body gets more pronounced in the concept of affective resonance, in which the interaction of bodies mutually constitutes both the subjects involved, creates a higher order derivative (resonance) which can be considered a distinct entity immanently resulting from these interactions.

8.4 From these sets of literatures and these different conceptualisations, it is possible to operationalise a concept of resonance on the basis of several key elements which seems consistent to the phenomena being described:

1. Resonance is an experience created in the moment as a temporary, ad-hoc, or fleeting form of meaningful association. In that sense, it lies outside the idea of enduring social structures, structures in the sense of sharing a formality, or mutual responsibility, commitment, or even a level of permanence. Instead, resonance is enacted and re-enacted in the present moment.

2. Resonance is an experience of belonging, intimacy, affinity, togetherness and mutual understanding In that sense, it is a meaningful and profound experience which separates it from the anonymous character of everyday life.

3. At the same time, resonance is not a ritual. It is not planned, and not exceptional to everyday life. It is a fundamental and important part of everyday experience, just not a ubiquitous one.

4. Resonance is an emotional connection based on appeals to sameness or common human experiences Without this feeling of 'sameness', or if appeals to common experiences go flat, then one can speak of dissonance, in which common experience and understanding is replaced by dissonant elements of uncertainty, anonymity and atomisation.

5. Resonance is embodied and experienced in physical co-presence Part of the appeal to 'sameness', and the momentary or fleeting nature of resonance involves its emergence from actors being engaged in common tasks, practices, and the 'doing' of life. This involves the interactions of bodies, gestures, and mutual physical engagement.

6. Resonance is an entity that can be considered distinct from the social interactions from which it emerged It is a co-production of bodies and subjectivities that, through processes akin to notions of 'feedback' or 'reverberation' in the physical sciences, create a phenomenon which is greater than the sum of its parts.

8.5 This paper started with the assertion that sociology had invested in a set of concepts which characterise modern urban life in terms of the individual/community or individual/social structure binaries. It went further to suggest that such an approach has created a sociological blind spot around forms of belonging that may fall in between these extremes. Shining light on this blind spot opens up considerable potential for sociology and sociological theory to grasp the more fleeting aspects of social life that have considerable impacts on our social experiences as well as our actions. Apart from a fuller theoretical understanding of everyday life itself, this paper 
has demonstrated that concept of resonance (although under-theorised) has already demonstrated value in the study of social movements, and that a more explicit and operational conceptualisation can contribute to discussions surrounding qualitative methodology and the relationship between researchers and subjects.

8.6 In addition, Benuza \& Stark (2012) have pointed to how resonance and dissonance can be used to explain the social dimensions of financial trading. In this case, they examined how stock trading 'mistakes' can be amplified by resonant group behaviours on the part of traders, suggesting a potential for resonance as a useful tool for conceptualising group behaviours within economic sociology.

8.7 The emphasis on embodiment as essential to the creation of resonance suggests that, in particular the sociology of health and illness could use resonance profitably. Freund (1990) put forward a similar agenda when he emphasised the underrated importance of emotions in the sociology of health at the time. Resonance can be used in the study of patient activism, particularly Embodied Health Movements, where emotionally-laden critiques of the bio-medical model of treatment, which objectifies both the disease and the body it inhabits (and separating both from the personhood of the patient) motivate patients to unite to push for changes in treatment procedures. For example, Brown et al (2004) examined the Environmental Breast Cancer Movement in the United States, where activists suffering with the disease used their collective bodily experiences of the disease and treatment histories to marshal widespread criticism of patient care. Resonance could also be valuable when discussing different forms of treatment regimes involving group dynamics, such as music therapy (Daykin et al 2007), and self-help groups (Adamsen \& Rasmussen 2003; Schrock et al 2004; Sandaunet 2007).

8.8 Urban sociology, investigating questions of social fragmentation and cohesion in urban space, through different forms of gentrification, gated communities and enclavism, and a general urban tendency for people to want to surround themselves with like-minded others, can benefit from considering resonance as another way of investigating phenomena which has recently been approached as 'scenes' (Straw 1991) or 'vibes' (Wu 2010). In these cases, resonance is both a positive feeling, and a potentially ghettoising force, where resonance is increasingly sought out in urban space, and dissonance is avoided. In this respect, it is worth pointing out that in considering resonance as a social phenomenon we should also consider the impact, and indeed the value of dissonance, and the process of having to come to terms with 'the unsettling'.

\section{Notes}

Hillary (1955) famously identified 94 definitions of community.

A terrible name, as 'tribe' refers to one of the most rigid forms of social structure. Not transitory or ephemeral at all.

The discussion of rave events in particular seems to be where the lion's share of discussion surrounding collective effervescence takes place (see Siokou 2002: Olaveson 2004).

Aside from these references, the notion of collective effervescence is little used within sociology. Again, this testifies to the claim made at the beginning of this paper that sociology and the social sciences in general tend to equate the social with enduring social structures or with the concept of 'community'.

This is premised of course on the idea central to Schutz's thought, as well as many others, that subjectivity is experienced through the other.

Similar to the production of an interview.

\section{References}

ADAMSEN, L., \& Rasmussen, J. (2003) 'Exploring and encouraging through social interaction: a qualitative study of nurses' participation in self-help groups for cancer patients'. Cancer Nursing, 26(1): p. 28-36. 
BAUMAN, Z. (1991). Modernity and Ambivalence, Cambridge: Polity.

BECK, U. and Beck-Gernsheim, E. (1995) The Normal Chaos of Love, Cambridge, Polity.

BENFORD, R.and Snow, D. (2000) 'Framing processes and social movements: an overview and assessment' Annual Review of Sociology. 26: p. 611-639.

BEUNZA, D., \& Stark, D. (2012). 'From dissonance to resonance: cognitive interdependence in quantitative finance'. Economy and Society, 41(3): p. 383-417.

BLUM, A. (2003) The Imaginative Structure of the City, London: McGill-Queen's University Press.

BROWN, P., Zavestoski, S., McCormick, S., Mayer, B., Morello?Frosch, R., \& Gasior Altman, R. (2004) 'Embodied health movements: new approaches to social movements in health'. Sociology of Health \& IIIness, 26(1): p. 50-80.

COBURN, W. (2001)' Subjectivity, emotional resonance, and the sense of the real', Psychoanalytic Psychology, 18 (2): p. 303-319.

DAUTENHAHN, K. (1997). 'I could be you: The phenomenological dimension of social understanding'. Cybernetics \& Systems, 28(5), p. 417-453.

DAYKIN, N., McClean, S. and Bunt, L. (2007) 'Creativity, identity and healing: Participants' accounts of music therapy in cancer care'. Health, 11(3): p. 349-370

DENZIN, N. K. (2001). 'The reflexive interview and a performative social science'.Qualitative Research, 1(1), p. 23-46.

DELEUZE, G. (1991) Bergsonism (H. Tomlinson \& B. Habberjam, Trans.). New York: Zone.

DELEUZE, G. (1994) Difference and Repetition (Paul Patton, Trans.). New York: Columbia University Press.

DIMOCK, W. (1997) 'A theory of resonance', PLMA, 112 (5): p. 1060-1071.

DUNSCOMBE, J. and Marsden, D. 1993. 'Love and Intimacy: The Gender Division of Emotion and "Emotion Work"', Sociology, 27: p. 221-241

DURKHEIM, E. (1912/1995) The Elementary Forms of Religious Life, New York: Free Press.

ETTEMA, J. (2005) 'Crafting cultural resonance: imaginative power in everyday journalism',Journalism, 6 (2): p. 131-152.

FERREE, M. M. (2003). 'Resonance and radicalism: feminist framing in the abortion debates of the United States and Germany'. American Journal of Sociology, 109(2): p. 304-344.

FERREIRA, C. (2004) 'Risk, transparency and cover up: media narratives and cultural resonance', Journal of Risk Research, 7 (2): p. 199-211.

FREUND, P. E. (1990) The expressive body: a common ground for the sociology of emotions and health and illness. Sociology of health \& illness, 12 (4), p. 452-477.

GIDDENS, A. 1992. The Transformation of Intimacy: Sexuality, Love and Eroticism in Modern Societies, Cambridge, Polity.

GUBRIUM, J. F., \& Holstein, J. A. (1998). Narrative practice and the coherence of personal stories'.The Sociological Quarterly, 39(1): p. 163-187.

HERMIDA-LAZCANO, P. (1996) 'The taken-for-granted world: a study of the relationship between A. Schutz and J. Orgega y Gasset', Human Studies, 19: p. 43-69.

HILLARY, G. (1955) 'Definitions of Community: Areas of Agreement,'Rural Sociology, 20: p. 111-123.

INGOLD, T. (1993) 'The temporality of the landscape', World Archaeology, 25 (2): 153-174.

JAMIESON, L. (1998) Intimacy: Personal Relationships in Modern Societies, Cambridge: Polity. 
JAMIESON, L. (1999) 'Intimacy transformed? A critical look at the 'pure relationship',Sociology, 33 (3): p. 477 494.

KVALE, S. (1983) 'The qualitative research interview: A phenomenological and a hermeneutical mode of understanding'. Journal of Phenomenological Psychology, 14 (2): p. 171-196.

MASSEY, D. (2005) For Space, London: Sage.

MAFFESOLI, M. (1996) The Time of the Tribes: The Decline of Individualism in Mass Society, London: Sage.

MALHORTRA, V. (1981) 'The social accomplishment of music in a symphony orchestra: a phenomenological analysis', Qualitative Sociology, 4 (2): p. 102-125.

MALINOWSKI, B (1923) 'Supplement 1: The problem of meaning in primitive languages' in C. Ogden and I. Richards (eds) The Meaning of Meaning, p. 296-336. London: Routledge \& Keegan Paul.

MEAD, G. (1963/1934) Mind, Self and Society from the Standpoint of a Social Behaviorist Chicago: University of Chicago Press.

MESTROVIC, S. (1993) The Barbarian Temperament: Toward a Postmodern Critical Theory, London: Routledge.

MISZTAL, B. (2003) 'Durkheim on collective memory', Journal of Classical Sociology, 3(2): p. 123-143.

MÜHLHOFF, R. (2014) 'Affective resonance and social interaction'. Phenomenology and the Cognitive Sciences, 13(3): p. 1-19.

NATANSON, M. (1986) Anonymity: A Study in the Philosophy of Alfred Schutz, Bloomington: Indiana University Press.

OLAVESON, T. (2001) 'Collective effervescence and communitas: processual models of ritual and society in Emile Durkheim and Victor Turner', Dialectical Anthropology, 26: p. 89-124.

OLAVESON, T. (2004) "'Connectedness" and the Rave Experience: Rave as New Religious Movement?' in Graham St. John (ed.) Rave Culture and Religion, New York: Routledge: p. 85-106

ORTEGA Y GASSET, J. (1957) Man and People. New York: Norton.

PLUMMER, K. (2003) Intimate Citizenship: Private Decisions and Public Dialogues, London: University of Washington Press.

ROBINETT, B. (2012) 'Emotional resonance, social location, and strategic framing'. Sociological Focus, 37 (3): p. 195-212.

ROSENEIL, S. and Budgeon, S. (2004) 'Cultures of intimacy and care beyond 'the family': personal life and social change in the early $21^{\text {st }}$ century', Current Sociology, 52 (2): p. 135-159.

SANDAUNET, A. (2008) 'The challenge of fitting in: non-participation and withdrawal from an online self-help group for breast cancer patients'. Sociology of Health \& IIIness, 30(1): p. 131-144.

SCHROCK, D., Holden, D., \& Reid, L. (2004). 'Creating emotional resonance: Interpersonal emotion work and motivational framing in a transgender community'. Social Problems, 51 (1): p. 61-81.

SCHUTZ, A. (1944) 'The stranger: an essay in social psychology',American Journal of Sociology, 49 (6): p. 499507.

SCHUTZ, A. (1964) 'Making music together: a study in social relationship' in A. Schutz,Collected Papers II: Studies In Social Theory. The Hague: Martinus Nijhoff: p. 159-179.

SHIELDS, R. (1996). 'Meeting or mis-meeting? The dialogical challenge to Verstehen'British Journal of Sociology, 47 (2): p. 275-294.

SHILLING, C. \& Mellor, P. (1997) Re-forming the Body: Religion, Community and Modernity, London: Sage.

SHILLING, C. \& Mellor, P. (1998) 'Durkheim, morality and modernity: collective effervescence,homo duplex and the sources of moral action', British Journal of Sociology, 49 (2): p. 193-209. 
SHILLING, C. \& Mellor, P. (2011) 'Retheorising Emile Durkheim on society

and religion: embodiment, intoxication and collective life', Sociological Review, 59 (1): p. 17-41.

SIMMEL, G., \& Hughes, E. C. (1949). 'The sociology of sociability'.American Journal of Sociology, 55 (3): p. 254261.

SIOKOU, C. (2002) 'Seeking the vibe', Youth Studies Australia, 21 (1): p. 11-18

SNOW, D. and Benford, R. (1988) 'Ideology, frame resonance, and participant mobilization', in H. Klandermans and S. Tarrow (eds.) From Structure to Action: Social Movement Participation Across Cultures, Greenwich: JAI: p. 197-217.

SONG, M and Parker, D. (1995) 'Commonality, difference and the dynamics of disclosure in in-depth interviewing', Sociology, 29 (2): p. 241-256.

STRAW, W. (1991). Systems of articulation, logics of change: communities and scenes in popular music.Cultural Studies, 5(3): p. 368-388.

SULLIVAN, H. S. (1954) The Psychiatric Interview (No. 506). WW Norton \& Company.

TURNER, V. (1969) The Ritual Process: Structure and Anti-Structure, New York: Aldine de Gruyter.

WIKAN, U. (1992) 'Beyond the words: the power of resonance', American Ethnologist, 19 (3): p. 460-482.

WU, E. M. (2010). Memory and Nostalgia in Youth Music Cultures: Finding the Vibe in the San Francisco Bay Area Rave Scene, 2002-2004. Dancecult: Journal of Electronic Dance Music Culture, 1 (2): p. 63-78.

ZELDIN, T. (1994) An Intimate History of Humanity, New York: Harper-Collins. 